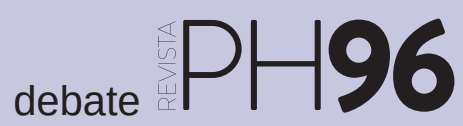

a debate Memoria democrática en la construcción de la historia y el patrimonio

| coordina Josefina Cuesta Bustillo

\title{
Los caminos tortuosos de las defensoras de la(s) memoria(s) de la posguerra peruana
}

José Ramos López | Círculo de Estudios José María Arguedas - UNSCH (Universidad Nacional de San Cristóbal de Huamanga, Perú)

URL de la contribución <www.iaph.es/revistaph/index.php/revistaph/article/view/4339>

Perú, una sociedad que mantiene cuentas pendientes con el pasado, se cobija bajo políticas de reparación obviando las políticas de memoria(s) reflejadas en la imperante cultura negacionista ${ }^{1}$, anclada en la memoria hegemónica protagonizada por héroes, excluyendo otras memorias en la patrimonialización promovida por el Estado. En este contexto, la sociedad civil nos da lecciones sobre experiencias de musealización de la memoria democrática y responsable.

Las narrativas sobre el conflicto armado interno² (19802000) han predominado la voz de hombres, situando las luchas por la memoria emprendida por las mujeres en el baúl del olvido, la sospecha y la indiferencia. Las líneas posteriores abordan la historia polivocal de mujeres que integran la Asociación de Familias Secuestradas, Detenidos y Desaparecidos del Perú (ANFASEP). Mujeres analfabetas, provenientes de comunidades campesinas, quechuahablantes que irrumpieron en el espacio público de los andes ayacuchanos un 2 de setiembre de 1983 para denunciar la desaparición de un familiar cercano.

A 35 años de vida institucional y 15 años de la entrega del Informe Final de la Comisión de la Verdad y Reconciliación han puesto en valor la memoria democrática desde una perspectiva de género, tales como el museo de la memoria de ANFASEP "Para que no se repita", inaugurado en 2006; La Hoyada: santuario de la memoria, lugar de memoria para el entierro digno de cuerpos exhumanos no identificados; intervenciones públicas performativas en torno a la memoria. Centramos nuestra atención en las mujeres rurales que compartieron su(s) memoria(s) para complejizar su agencia política y el papel de reconstruir la sociedad peruana.

\section{Rompiendo estructuras de dominación}

Nos encontramos con un conjunto de paquetes que complejizan la violencia y que el sujeto, que es mujer y procedente de la comunidad andina, está lleno de memorias (GAMARRA, 2002; DEL PINO, 2003), se moviliza a la ciudad y opta por diferentes mecanismos para poder solventarse, tener una vida digna, un techo propio y, en pocos casos, reclamar sus derechos. Ubicadas en los asentamientos humanos, caracterizados por abismales brechas sociales, económicas, étnicas donde se les percibe como "insignificantes: pobres, rurales, indígenas, mujeres. $Y$ vuelve a reaparecer la trenza de discriminaciones y desprecios." (DEGRÉGORI, 2015: 260). Empero, la vivencia del conflicto armado interno y la violencia rutinizada no terminan consumiendo y opacando a las actrices sociales. Si reparamos el uso, la invención y re-invención de la parafernalia de estrategias culturales para poder salir de estos ciclos de violencia, veremos que las actoras sociales innovaron nuevos sentidos de género, utilizaron su presupuesto cultural para desarrollar la capacidad de resiliencia.

En este contexto de la post-guerra, la mujer "se propone legitimar su presencia y respaldar sus espacios ganados ubicándose como sujeto social en las tareas de reconstrucción y desarrollo local" (CORAL, 1999: 359). Dicha autora nos muestra la participación en tres etapas: un antes, en el cual la mujer era invisibilizada, donde cumplía roles domésticos; luego, un periodo de conflicto, donde la mujer sufre una infinidad de vejámenes que se arraigan en lo más profundo de su subjetividad; y, por último, en la post-guerra, en el cual predominan las jefaturas y las mujeres son visibilizadas porque emprenden demandas sociales de reconocimiento y reparación por parte del Estado. 
a debate Memoria democrática en la construcción de la historia y el patrimonio

| coordina Josefina Cuesta Bustillo

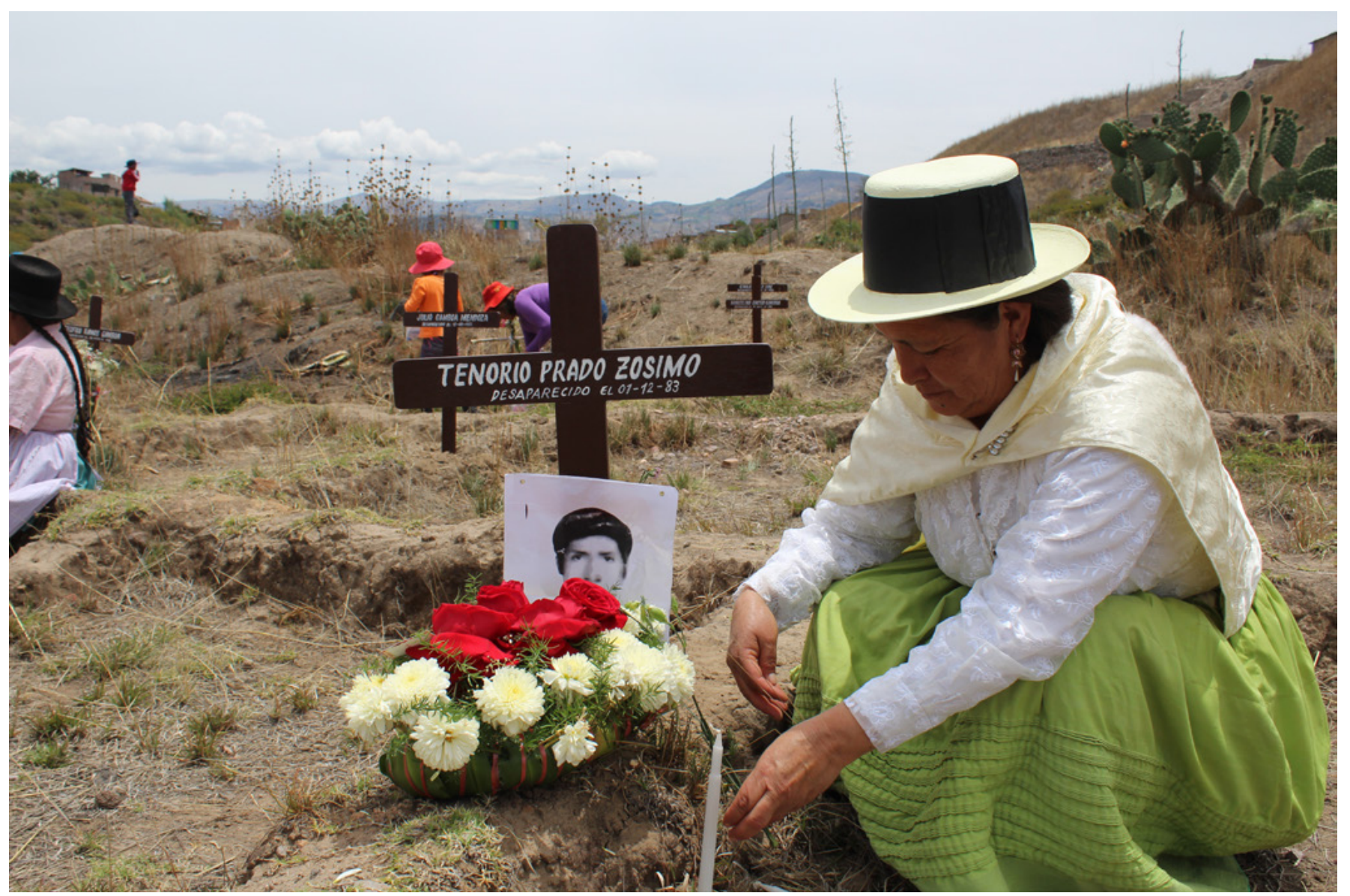

Adelina Mendoza, lideresa de ANFASEP, conversa con su esposo desaparecido en La Hoyada, Santuario de la memoria

La asignación casi completa de responsabilidades y la sobrecarga de trabajo hacia la mujer propiciaron un escenario fértil para la participación en espacios públicos y representativos. En consecuencia, las ideas sobre género entraron en un proceso de re-significación como "warmikunaqa qari hina karaniku"3, "Las mujeres pues tenemos más fuerza para podernos recuperar", "padre y madre he sido para mis hijos". Se contempla la anexación de los roles tradicionales que el varón cumplía para un nuevo sentido de género conocido como mujer "warmi-qari" (mujer-varón). La acepción anterior era una característica propia de las mujeres viudas que tenían mayor acceso a los espacios públicos, eran "warmisapas"4 (THEIDON, 2004: 131). Se empiezan a redefinir las estructuras de género y relaciones identitarias, las femineidades a partir de la situación de las masculinidades. Quienes estaban "ausentes", en sentido físico, en sus hogares.

Muchos de los testimonios recolectados por la Comisión de la Verdad y Reconciliación y la literatura antropológica sobre la violencia política nos muestran que las mujeres tienden a priorizar el bienestar de los "otros", así como comentar sobre los problemas de sus hijos, sobre cómo desapareció su familiar y las acciones de búsqueda irrenunciable. Dedicándole un reducido tiempo para sus sentimientos. Sin embargo, puede parecernos una paradoja pero a través del cuidado de los otros se cuida también ella. "No voy a las atenciones, ni al hospital para curarme. Mis hijos son primero, si están bien ellos yo tam- 
bién estoy." Una moral del cuidado (GILLIGAN, 1982), una maternidad hegemoniza las representaciones discursivas de sus vidas que las hace aparecer como heroínas. Adicionalmente impera un imaginario social sobre la capacidad desarrollada por las mujeres de hacer frente a la realidad adversa, de asumir con gran responsabilidad los espacios de representación, producto de una continuidad política venidera desde las organizaciones que proceden como comedores populares, organizaciones gremiales del mercado, organizaciones de búsqueda de personas.

\section{Estrategias culturales y ganando la posguerra}

"Lo que he sufrido me ha hecho abrir los ojos, hemos madurado mucho, las mujeres hacemos bien nuestros cargos, con responsabilidad; en cambio los varones se gastan bebiendo. Nosotras no"5

El dolor, la incertidumbre de sus familiares, la violencia experimentada se convirtieron en fuerzas motoras para sobresalir de su condición de mujer, víctima, desprotegida, relegada, y legitimarse en espacios económicos, sociales y políticos haciendo uso de un repertorio discursivo que cambia de acuerdo a la población. En las reuniones internas de ANFASEP, la representación discursiva de la mujer gira alrededor de la valentía, la fuerza de sobreponerse y la capacidad de resiliencia. Mientras que en reuniones multisectoriales la representación discursiva se agrupa en la victimización por la sociedad y el Estado poniendo énfasis en las constantes discriminaciones que experimentan y el poco compromiso de buscar la verdad.

Todo el repertorio de mecanismos culturales utilizados en la sociedad de la posguerra insiste en re-conocer la capacidad de resistir, sobreponerse y salir de experiencias dolorosas (GAMARRA, 2010). Es decir, la resiliencia cultivada por las mujeres les abrió un abanico de oportunidades, transitando del dolor hacia la acción y construcción de ciudadanía y desarrollo (REYNAGA, 2008). Los puntos de inflexión provocan una respuesta emocional y cognitiva permitiendo darle la vuelta al problema y buscar agujeros de escape para aprovecharlos de cierta

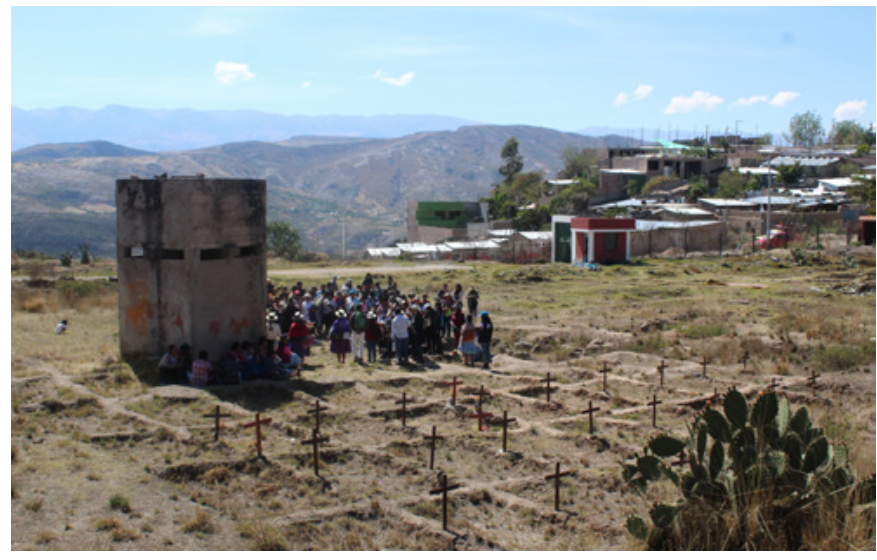

Madres ayacuchanas al costado del tanque de combustible, lugar donde los militares del cuartel "Los Cabitos N51" cremaron cuerpos en los años de violencia

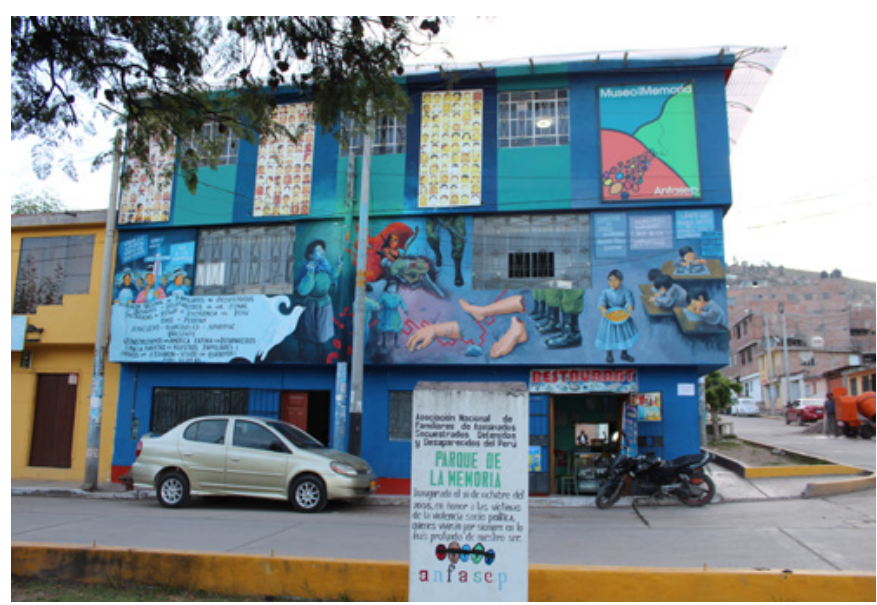

Museo de la memoria "Para que no se repita" muestra de manera pedagógica los años de violencia, gestionada por ANFASEP y ubicado en Ayacucho, Perú fotos José Ramos López (Ayacucho, 2019)

manera. La resiliencia no solo opera en aspectos psicológicos sino, más bien, en las distintas dimensiones de la vida. Pero tres componen las regularidades en la vida de las mujeres: primero, en las argucias económicas (responsabilidades sobrecargadas); segundo, en el ámbito público (mayor inserción); y tercero, el manejo de las emociones y sentimientos.

Entonces, abordar estos problemas debe de "contribuir a discernir lo que somos como país, incluyendo la 


\author{
a debate Memoria democrática en la construcción de la historia y el patrimonio \\ | coordina Josefina Cuesta Bustillo
}

exclusión y las desigualdades persistentes, la falta de ciudadanía y la débil institucionalidad política". Carlos Iván Degregori proponía que una política de memoria en el Perú debía contribuir a un "nunca más" de la violencia, pero también a un "nunca más" de la exclusión, un "nunca más" de poca ciudadanía y un "nunca más" de la extrema pobreza (DEL PINO; AGÜERO, 2014: 24). Es decir, dar un buen tratamiento y lectura cultural de la memoria para poder vivir en una sociedad, en la cual potenciemos la convivencia y coexistencia social con criterios tolerantes. Las experiencias anteriores son una forma de ganar la posguerra de poco a poco.

\section{NOTAS}

1. El otorgamiento del indulto al ex presidente Alberto Fujimori, sentenciado por la violación de derechos humanos mediante un grupo paramilitar Grupo Colina en los casos de Barrios Altos y La Cantuta, obedece a dicha memoria negacionista situada en el poder político de legisladores distorsionando el sentido de la reconciliación.

2. Categoría que hace alusión a los veinte años de violencia protagonizada por Sendero Luminoso, grupo alzado en armas, y las Fuerzas Armadas, ocasionando 2329 desaparecidos, 69.000 víctimas, más de 600.000 desplazados y aproximadamente 5000 sitios de entierro clandestino.

3. Las mujeres éramos como los varones.

4. Mucho más que una mujer o doblemente mujer.

5. Conversación con una socia de ANFASEP.

\section{BIBLIOGRAFÍA}

- DEGRÉGORI, C. I. (2015) Heridas abiertas, derechos esquivo. Derechos humanos, memoria y Comisión de la Verdad y Reconciliación, Obras escogidas (Vol. IX). Lima: IEP, 2015

- DEL PINO, P. (2003) Uchuraccay: Memoria y representación de la violencia política en los Andes. En DEGRÉGORI, C. I. Jamás tan cerca arremetió lo lejos: Memoria y violencia política en el Perú. Lima: IEP, 2003, pp. 49-93

- DEL PINO, P.; AGÜERO, J. C. (2014) Cada uno, un lugar de memoria. Fundamentos conceptuales del Lugar de la Memoria, la Tolerancia y la Inclusión Social. Lima: LUM, 2014

- CORAL, I. (1999) Las mujeres en la guerra: impacto y respuestas. En STERN, S. Los senderos insólitos del Perú: guerra y sociedad, 1980-1995. Lima: IEP-UNSCH, 1999, pp. 337-363

- GAMARRA, J. (2002) Las dificultades de la memoria, el poder y la reconciliación: documento de discusión. Ayacucho: IPAZ, UNSCH, 2002

- GAMARRA, J. (2010) Resiliencia social y cambio en comunidades campesinas afectadas por conflicto armado interno: el caso de las comunidades de Incaraccay y Tanquihua en la provincia de Cangallo, Ayacucho. Lima: IPEDEH, 2010

- GILLIGAN, C. (1982) La moral y la teoría: Psicología del desarrollo femenino. México: Fondo de Cultura Económica, 1982

- REYNAGA, G. (2008) Respuesta de las mujeres ayacuchanas frente a los problemas de la violencia política [en línea]. Tesis para optar el grado de Magister en Gerencia Social. Lima: PUCP. <http://tesis.pucp.edu.pe/repositorio/ handle/123456789/1106> [Consulta: 21/12/2018]

- THEIDON, K. (2004) Entre prójimos. El conflicto armado interno y la política de la reconciliación en el Perú. Lima: Instituto de Estudios Peruanos, 2004 